\title{
Editorial: A Tribute to Yevgeniy Nikolaievich Sokolov (1920-2008)
}

On May 14, 2008, Professor Yevgeniy Nikolaievich Sokolov, of the M.V. Lomonosov Moscow State University, passed away at the age of 87. Professor Sokolov was born on September 23, 1920, in a family of civil servants residing in the city of Nizhni Novgorod (Gorki). In 1939, he finished General Education with honors at School nr. 2 of Gorki. In 1940, he enrolled in the Department of Naval Construction of the Industrial Institute of the same city. The German invasion of the Soviet Union interrupted his studies, and he joined the Soviet Army as a translator in the Intelligence Units. Due to war merits, he was awarded the Order of the Red Star, the Order of the Great Patriotic War and the medals For the Victory over Germany in the Great Patriotic War 1941-1945, For the Defense of Moscow and For the Liberation of Warsaw. Between 1945 and 1946, he studied at the Maurice Thorez Pedagogical Institute of Moscow of Foreign Languages (specialty: modern German language), concluding his studies as an external student in only two years.

In 1947, he carried out his doctorate studies in the Psychology Section of the Philosophy Institute of the Academy of Sciences of the USSR. This Psychology Section was directed by Sergey Leonidovich Rubinstein (1889-1960), who founded it in 1945 in the Philosophy Institute, within the framework of the Psychological Laboratory of Professor Sergey Vasilievich Kravkov (1893-1951). There, Sokolov wrote his Candidature Thesis. The main topics that interested Kravkov (the interaction of the sensory organs, the nature of color vision, and the electrophysiology of visual perception) had a notable influence on Sokolov's research interests. His Candidature Thesis, entitled Issues of Psychology of Perception from the Pavlovian Approach was defended in 1950 and, besides the analysis of the Pavlovian heritage, it also included the results of specific investigations of the mechanisms of visual perception (subsequently, in 1958, these data were summarized in the famous monograph Perception and the Conditioned Reflex). Professor Kravkov, being a collaborator of the Philosophy Institute, also carried out his investigations in the Psychology Institute of the Academy of Pedagogical Sciences of the USSR, because in the latter, in contrast to the Philosophy Institute, there were proper conditions to perform real experiments. Sokolov also carried out many experiments there. In 1950, Sokolov was invited by Boris Mijailovich Teplov (1896-1965) to the Moscow State University (MSU) to the Psychology Department of the Philosophy Faculty, directed by Teplov (S. L. Rubinstein had been dismissed and was only replaced in 1956 in the Psychology Section of the Philosophy Institute of the Academy of Sciences of the USSR). Between 1950-1960, Teplov's scientific work involved the psychophysiology of individual differences, based on Pavlov's theory of the properties of the types of nervous system. Sokolov worked in the Laboratory of Analyzers attached to the Psychology Department of the Philosophy Faculty. His first psychophysiological investigations in the MSU were devoted to the study of the sensory processes involved in the formation of the mechanism of creation of the elemental (primary) sensations of light and sound. Subsequently, these investigations were extended to include investigations of the orientation reflex. Sokolov continued this work in collaboration with the Physiology Department of Higher Nervous Activity of the Biology Faculty of the MSU. During these investigations, methods were developed to study the structure of the orienting reaction at different stages of the appearance of the conditioned reflex; an original model (which is still current nowadays) was proposed: "the nervous model of the stimulus," which explained the dynamics of extinction (and recovery) of the orienting reaction.

Correspondence concerning this editorial should be addressed to Javier Bandrés, The Spanish Journal of Psychology, Facultad de Psicología, Campus de Somosaguas.28223 - Madrid (Spain). E-mail: psyjour@psi.ucm.es 
In 1953, Alexandr Romanovich Luria (1902-1977) offered Sokolov a second post at his Laboratory in the Institute of Defectology of the Academy of Pedagogical Sciences of the USSR, where objective recording methods of vegetative and electroencephalographic reactions were employed to diagnose vision and hearing alterations. Here, together with other collaborators of the Institute, Sokolov investigated the mechanisms of perception and orientation activity, as well as the interaction of the two signal systems in normal and pathological activity. In the summer of 1954, following the recommendation of Alexei Nikolayevich Leontiev (1903-1979), Sokolov was included in the delegation that participated in the XIV Psychology Congress in Montreal.

The first psychophysiological investigations in the University of Moscow that led to the formation of an independent school of Russian psychophysiology were conceived and carried out according to Sokolov's initiative in the 1950s and 60s in the Laboratory of Analyzers attached to the Psychology Department of the Philosophy Faculty. During this stage, the center of interest focused on the study of the orienting reflex discovered by Pavlov, the unconditioned-reflex reaction to novel stimuli. All these data were summarized in a classic book, Perception and the Conditioned Reflex (1958), which had great international impact and was published in the USA, the UK, Japan, Argentina, and Mexico. Sokolov taught courses on this topic in 1960, as a Visiting Professor in the Universities of Stanford and California in the USA. In 1960, Sokolov achieved his Doctorate Degree in Biology and in 1962, he was appointed Psychology Professor. In 1964, under the direction of Sokolov and with his direct participation, many psychophysiological investigations on memory and learning were carried out in the Laboratory of Analyzers. The investigation began by studying the functions of memory and learning from the psychological viewpoint and concluded with the analysis of physiological mechanisms. Memory was analyzed with the model of extinction of the orienting reflex (negative learning) at a macroscopic level, and with the study of the effects of the trace on neurons at the microscopic level. As a result of these investigations of the intracellular mechanisms of memory, the effect of habituation of each neuron, which underlies the mechanism of memory, was described. Neural mechanisms were discovered of two completely different types of learning: learning dependent on the organization of information and learning dependent on the organization of the response action (stimulusdependent and effect-dependent learning, respectively). The results of this set of laboratory works were published in Sokolov's book Mechanisms of Memory (1961) and the series of conferences he presented at the University of Moscow, the Universities of Cambridge and Oxford (UK), the MIT Psychology Cathedra in the USA (1974), and also at the Universities of Sophia and Budapest (1975).

In 1971, with the support of the Faculty Dean, Professor Leontiev, and of Professor Luria, the Department of Psychophysiology of the Psychology Faculty of the MSU was founded, and directed by Sokolov from the time of its creation until 1999. The department continued to investigate the mechanisms of perception, memory, and learning, and the functional states of the brain, and psychophysiological investigations of semantics, emotions, and stress were also initiated. As an outcome of the synthesis of the results of these investigations performed from the "person-neuron-model" approach, Sokolov formulated the general principles of the organization of sensory and executive systems of the brain in the form of the conceptual reflex arc model and, subsequently, he developed the vectorial approach to the re-elaboration of information in neural networks, based on this model. The vectorial approach merges, within the framework of a single non-contradictory system, the concepts of detection and connection from the sensory information coding theory. In fact, according to this approach, the vectorial coding principle also extends to the neural mechanisms of the executive and modeling mechanisms, which could explain the surprising consonance in the interaction of the sensory levels and behavior. The results of this series of investigations were reflected in the cycle of conferences presented by Professor Sokolov in 1996 in the University of St. Louis in Washington (USA) and also in a series of innovative special courses, prepared and directed by Sokolov for the students of the university of Moscow: Psychophysiology of Gestalt, Mechanisms of Memory and Learning, Mechanisms of the Orienting Reflex and the Orientation-Investigation Activity, Mechanisms of the Conscience and Vectorial Psychology. The main thesis of the vectorial theory of the 
cognitive processes and executive mechanisms and their experimental fundamentals were presented in several main monographs. Artificial Sensory Organs (with G. G. Vaitkevicius and S. V. Fomin, 1979), Psychophysiology (1981), Neurobionics (with L. G. Shmelev, 1983), Neural Mechanisms of the Memory and Learning (1984), Theoretical Psychophysiology (1986), Psychophysiology of Color Vision (with Ch. A. Izmailov and A. M. Chernorizov, 1989), Neurointellect: From Neurons to Neurocomputer (with G. G. Vaitkevicius, 1989), The Orienting Response in Information Processing (with J. A. Spinks, R. Naatanen, and H. Lyytinen, 2002), Perception and the Conditioned Reflex: A New Look (2003) and Sketches of the Psychophysiology of Consciousness (2008).

In 1995, through the initiative of Sokolov, the Center for Research of Magnetic Resonance Tomography was founded in the M. V. Lomonosov State University of Moscow, which cleared the way to new horizons for the development of Russian neuroscience and for experimental investigations at an international level.

Having devoted his whole life to psychophysiology, Sokolov was aware, more than anyone else, of all the complexity of the borderline location of this science, which evolves at the intersection of psychology, biology, and mathematics. Therefore, he dedicated special attention to the development of the general methodology of current psychophysiology, understood as the science of the neural mechanisms of psychological processes and states. The results of the analysis of the topic and of the data of current psychophysiology in the framework of the Man-Model-Neuron approach proposed by Sokolov are reflected in the above-mentioned works Psychophysiology (1981), Theoretical Psychophysiology (1986), and in reviews of the last few years: Perception and the Conditioned Reflex. A new look (2003), and Sketches of the Psychophysiology of Consciousness (2008).

When developing Russian psychophysiology as an inseparable part of world science, Sokolov initiated numerous international scientific research projects, carried out in the Psychophysiology Department together with foreign co-workers: The interrelation of the phasic and tonic orienting reflex (in collaboration with the university of New South Wales, Australia), Color Image (in collaboration with the Vision Institute of the University of Eindhoven, Holland), Mechanisms of Color Vision (in collaboration with the University of G. Washington of Seattle, and the University of St. Louis, USA), Mechanisms of Color Contrast and Brilliance (in collaboration with the Vision Institute of the University of Eindhoven, Holland, and the Psychology Department of the University of Helsinki, Finland), and Psychophysiology of the Emotions (in collaboration with the University of Wuppertal, Germany).

Like a true "Master", Sokolov dedicated much of his time to working with students and disciples. The essential principle of the preparation of specialists that he preached all his life was that of "learning through investigation." This approach to learning means that, from the very start of his or her specialization, the student was included in a real work of scientific research. Specialization was carried out via a special practicum and the system of special courses dedicated to the appraisal of the current theories and the experimental data from Russian and foreign psychophysiology. According to Sokolov's proposal, in 1995, a new special practicum, entitled Fundamentals of Neurosciences, was developed and introduced into the teaching process in the Psychophysiology Department. It was a base for the "learning through investigation" of the profession and focused on acquiring current knowledge in various areas of Neurobiology and psychophysiology. Sokolov foresaw that one of the important tasks of this multidisciplinary practicum would be the creation in the Psychology Faculty of a scientific and pedagogic base to open a new specialty in the University of Moscow: in the field of neuroscience.

Both the Russian and the international scientific community acknowledged the professional and scientific category of Professor Sokolov with numerous awards. In his country, he was awarded for his professional merits the Order of the Red Labor Badge and the medals: For Labor Merit, For Valiant 
Labor, and In Commemoration of the $100^{\text {th }}$ Anniversary of the Birth of Vladimir Ilich Lenin. Also in his country, for his scientific merits, he was awarded the I. P. Pavlov Gold Medal of the Academy of Sciences of the USSR, the M. B. Lomonosov Prize, the title of Honorary Professor of the University of Moscow, and the Presidential Award. Outside of his country, the extraordinary merits of Professor Sokolov were acknowledged by diverse awards. In 1988, the American Association of Psychophysiological Research awarded Sokolov a special diploma "for the extraordinary contribution to psychophysiology," with which it rewards scientists who work in basic investigation and whose works have a notable impact on the development of science. At the XI Congress of the International Association of Psychophysiologists, held in Italy in September of 1998, the highest prize of the Association-the Prize of the Century-was awarded to five eminent psychophysiologists from all over the world: H. H. Jasper, E. N. Sokolov, D. Lindsley, J. Delgado, and N. P. Bekhtereva. The prizes were awarded for the excellent contribution of these scientists and of the scientific collectives they direct in the development of psychophysiology and related sciences. Professor Sokolov also belonged to some of the most important scientific academies of the world: He was a member of the Russian Education Academy, the Medical-Technical Sciences Academy of the Russian Federation, the Academy of Sciences of Finland, the National Academy of Sciences of the USA, and the Academy of Arts and Sciences of the USA.

The colleagues and friends of Yevgueni Nikolayevich Sokolov, his students and disciples who worked in diverse countries all over the world and the Board of Editors of The Spanish Journal of Psychology — which has the honor of publishing some of his last experimental investigations - mourn the disappearance of the Master, Professor, and Person. In our hearts will always remain the clear remembrance of a person with extraordinary vital force and warmth of spirit, a person who, like nobody else, did all he could to fulfill the words of another great Russian scientist, who also passed away recently, P. V. Simonov: "I am convinced that the $21^{\text {st }}$ century that is approaching will be the century of Psychophysiology in its two hypostases: neurobiological and psychological, of natural and human sciences. The new methods of neuroscience will enrich us with knowledge about the functioning of the brain, about which our great predecessors could, at best, only make assumptions, and psychology, by becoming a true science, will essentially enrich our knowledge of man."

Alexandr N. Chernorizov, Adriana Dergam, Javier Bandrés 